\title{
RE-DESIGN DO ATOM PARA CURADORIA DIGITAL EM AMBIENTES E COMUNICAÇÃO MUSEOLÓGICA
}

\author{
RE-DESIGN OF THE ATOM FOR THE DIGITAL \\ CURATION IN DIGITAL ENVIRONMENTS AND \\ MUSEOLOGICAL COMUNICATION
}

\author{
Lucineia da Silva Batistaa \\ Maria José Vicentini Jorente ${ }^{b}$
}

\begin{abstract}
RESUMO
Objetivo: Essa pesquisa tem por objetivo estudar a possibilidade de utilizar o AtoM para a descrição e representação dos objetos museológicos, especificamente em museus históricos.

Metodologia: A pesquisa é por característica teórica e exploratória participativa com a realização de um levantamento teórico sobre a Curadoria Digital e a descrição museológica, no espaço dialógico da Ciência da Informação e de uma comparação dos formulários descritivos do AtoM com o modelo descritivo das Diretrizes de Informação para Museus do CIDOC de 1995.

Resultados: Como resultado, o AtoM representou o acervo histórico de maneira satisfatória e apresentou muitas funcionalidades que torna flexível a adaptação de certos problemas emergentes.

Conclusões: A pesquisa cujos resultados ora encaminhamos ao mesmo tempo em que apresenta uma resposta a questão apresentada, vê-se emergir a necessidade de mais pesquisas aprofundadas nas normas museológicas que possam contribuir para uma possível customização do AtoM, capaz de atender às necessidades mais complexas das instituições museológicas e favorecer a democratização e acesso à herança cultural, em ambos os ambientes, físicos e digitais as gerações presente e futura.
\end{abstract}

Descritores: Curadoria Digital. Design da Informação. Acervos Museológicos. AtoM.

\section{INTRODUÇÃO}

As Tecnologias de Informação e Comunicação (TIC) ampliam os espaços

\footnotetext{
a Doutoranda do Programa de Pós-graduação em Ciência da Informação pela Universidade Estadual Paulista (UNESP), campus de Marília. E-mail: lucineia.bat@gmail.com

b Doutora em Ciência da Informação pela Universidade Estadual Paulista (UNESP). Docente em Cultura Digital e informação pós custodiada em Redes de Colaboração e do Programa Programa de Pós-graduação em Ciência da Informação pela Universidade Estadual Paulista (UNESP). E-mail: mj.jorente@unesp.br
} 
de atuação das instituições biblioteconômicas, arquivísticas e museológicas que, além dos seus espaços físicos, contam com ambientes digitais para o acesso e compartilhamento de informações relevantes: tratam-se de representações digitais de seus acervos no entorno digital. $O$ acesso a essas representações por sujeitos informacionais, ou internautas, depende de que os acervos sob custódia (em bibliotecas, arquivos e museus) passem pelo processo de Curadoria Digital (CD) para garantir a sua preservação digital para a sociedade atual e futura.

Os museus, em sua maioria, constituem-se de objetos musealizados na formação de suas coleções. Tais objetos são formas de manifestações culturais materializadas pelo homem e compreendidas como testemunhos da existência de uma determinada cultura e sociedade. Partem das convergências entre suportes e informação passíveis de serem acessadas e recuperadas a partir do registro documental, que deve incluir a descrição dos artefatos e de seu contexto histórico, no setor de documentação dos museus. A documentação justifica a preservação do objeto na instituição museológica, pois, sem ela os museus tornar-se-iam meros armazéns de objetos (ZUBIAUR CARREÑO, 2004).

A CD se consiste de ações estruturais e práticas, pensadas e aplicadas antes e durante todo o processo curatorial, que trata, gerencia e preserva a herança cultural e, de certa forma, contempla a elaboração da documentação nos acervos de museus. Destaca-se a utilização de sistemas voltados à preservação digital e à descrição e representação da informação no processo de curadoria. Nos Museus, o sistema de documentação facilita as atividades, a conservação, a exposição e até a luta contra o tráfico ilícito de bens culturais (ZUBIAUR CARREÑO, 2004), além da ampliação e democratização do acesso à informação e à cultura.

Díaz Balerdi (2008) apresenta as atividades que envolvem a metainformação do objeto museológico: o inventário, a catalogação, o banco de dados, as informações periféricas e a bibliografia complementar - elementos que proporcionam a comunicação imediata entre a obra (objeto) e o internauta presentes nos sistemas digitais de descrição e de representação.

Nesse contexto, apresentam-se $\circ$ AtoM e o Archivematica, sistemas convergentes e fundamentais para a descrição e a preservação das 
representações digitais de acervos, pois, com a sua aplicação conjunta, o processo de CD é completo.

O AtoM é um sistema de descrição e representação, baseado em normas arquivísticas e voltado, originalmente, às instituições de arquivo. Contudo, identificou-se sua utilização por algumas instituições consideradas "híbridas" tanto no contexto nacional quanto internacional": são museus e arquivos considerados híbridos pela tipologia dos seus acervos, ou ainda, arquivos de museus. No contexto internacional, destacam-se: Archival holdings at the Museum of Anthropology, University of British Columbia, de Vancouver; Museum of Croydon Collections, de Londres; Musée Héritage Museum Archives, de St. Albert-Canada; o Jewish Museum \& Archives of British Columbia, em Vancouver; L'arxiu del Museu d'Història de Barcelona, em Barcelona; Royal British Columbia Museum and Archives, em Victoria-Canada; Whistler Museum and Archive, na British Columbia-Canada; Air Force Museum of Alberta Archives, em Alberta; Cumberland Museum and Archives, em Cumberland-Canada.

O Museu e Arquivo de Cumberland destaca-se devido ao "Chinese Canadian Artifacts Project', que possui 6.000 artefatos chineses descritos, representados e disponíveis no AtoM. O projeto iniciou-se em 2015 na Universidade de Victoria e teve apoio da BC Museums Association e a parceria de 16 museus para a elaboração das descrições. A iniciativa surgiu com vistas à comemoração da contribuição chinesa na província Colúmbia Britânica no passado, mas também um pedido de desculpas oficial aos erros históricos cometidos contra os canadenses de origem chinesa.

No contexto nacional, além do Museu Histórico da Faculdade de Medicina da Universidade de São Paulo, há também a descrição de objetos museológicos salvaguardados e custodiados no Laboratório de Design e Recuperação de Informação - LADRI, localizado no Centro de Documentação Histórica e Universitária de Marília (CEDHUM) e vinculado à Faculdade de Filosofia e Ciência (FFC) da Universidade Estadual Paulista (UNESP). O acervo da FFC é composto por objetos heterogêneos, utensílios pessoais, domésticos, de cozinha, de montaria, religiosos, de guerra, de caça, de iluminação, ligados ao ensino, entre outros. São parte de um todo maior, das coleções de objetuária de 
naturezas diversas, pertencentes aos diferentes Campi da UNESP.

Ao considerar a CD da herança cultural, representada por tais objetos, e a necessidade de inseri-los em um processo de preservação digital, questionouse a possibilidade de o AtoM ser utilizado para a descrição de objetos museológicos, (primeira e especificamente em museus históricos) conjugado ao Archivematica, para a preservação dos objetos digitais derivados.

Identificaram-se preocupações semelhantes sobre a utilização do AtoM em museus no fórum AtoM Users, criado na plataforma Google - discussões identificadas com os títulos: "Spectrum standard and ICA-AtoM" (2013); "AtoM for Museum Colletion" (2017); e "Using AtoM to document museum collection" (2019). Dan Gillean, Gerente de Programa AtoM (da empresa Artefactual System), apresenta sugestões aos questionamentos levantados, e alega: "eu conheço muitos museus sem acervos de arquivo que estão atualmente usando o AtoM" (2019).

Nesse sentido, a pesquisa que partiu do questionamento inicial foi de característica teórica e exploratória participativa. Realizou-se, inicialmente, um levantamento teórico sobre Curadoria Digital, Representação da Informação e Descrição Museológica, no espaço dialógico da Ciência da Informação. Na pesquisa exploratória, buscou-se, primeiro, conhecer as funcionalidades do sistema AtoM. Posteriormente, comparou-se o modelo descritivo do AtoM com o modelo descritivo das Diretrizes de Informação para Museus do CIDOC, de 1995, para a verificação de quais campos descritivos especificamente museológicos são atendidos pelo sistema; e quais ele não atende.

Destaca-se a importância da utilização do acervo museológico da FFC em um Projeto de Extensão, que se iniciou em 2014 e terminou em 2018, para essa pesquisa: o AtoM no processo de descrição, conjugado ao Archivematica para a $\mathrm{CD}$, com vistas ao acesso à comunidade e a preservação digital das representações resultantes. Também, se justifica a necessidade de respostas acadêmicas referentes à criação de um Modelo para a utilização do AtoM em museus com vistas à descrição e à representação da herança cultural em ambientes digitais, garantindo seu acesso e sua preservação a longo prazo. 


\section{CURADORIA DIGITAL}

Segundo Sabharwal (2015) a curadoria passou por mudanças em sua definição, até então enraizada nas práticas do século XIV e associada a artefatos museológicos. As influências das Tecnologia da Informação e Comunicação (TIC) emergentes $\mathrm{e}$ as decorrentes necessidades de reconhecer interdisciplinaridades nas práticas da Ciência da Informação são responsáveis pela origem do conceito Curadoria Digital (CD) - com características interinstitucionais e interdisciplinares, que requerem o "conhecimento de tecnologias aplicáveis que não foram incluídas nas práticas de curadoria prédigital e envolve um ciclo de vida" (SABHARWAL, 2015, p. 14, tradução nossa). Para o autor, os objetos digitais, incluídos nos acervos museológicos existentes a serem acessados, exigem novos métodos de preservação no ambiente digital.

Em 2004, foi criado o Digital Curator Centre (DCC), um centro de serviço colaborativo distribuído e voltado à curadoria de informações digitais, para tratar das transformações conceituais e práticas derivadas da ampliação de artefatos resultante da somatória entre acervos e seus representantes digitais (HIGGINS, 2011). De acordo com o DCC (2004, tradução nossa) a CD é "o gerenciamento e preservação de dados/informações digitais em longo prazo".

Em 2007, Sara Higgins apresentou um Modelo de Ciclo de Vida para o processo de $\mathrm{CD}$ de objetos digitais ou digitalizados, posteriormente adotado pelo DCC. O modelo permite uma visão geral dos estágios de uma curadoria adequada e identifica as ações sequenciais de curadoria dentro do ciclo de vida do objeto digital (HIGGINS, 2008). As ações podem "garantir a manutenção de autenticidade, confiabilidade, integridade e usabilidade do material digital" (HIGGINS, 2008, p. 135, tradução nossa).

A partir da conceitualização, o modelo dispõe uma visão macro (de estruturação) e micro (de implementação) da CD a serem pensadas e colocadas em prática, como mostra a figura 1: 


\section{Figura 1 - Modelo do Ciclo da Curadoria}

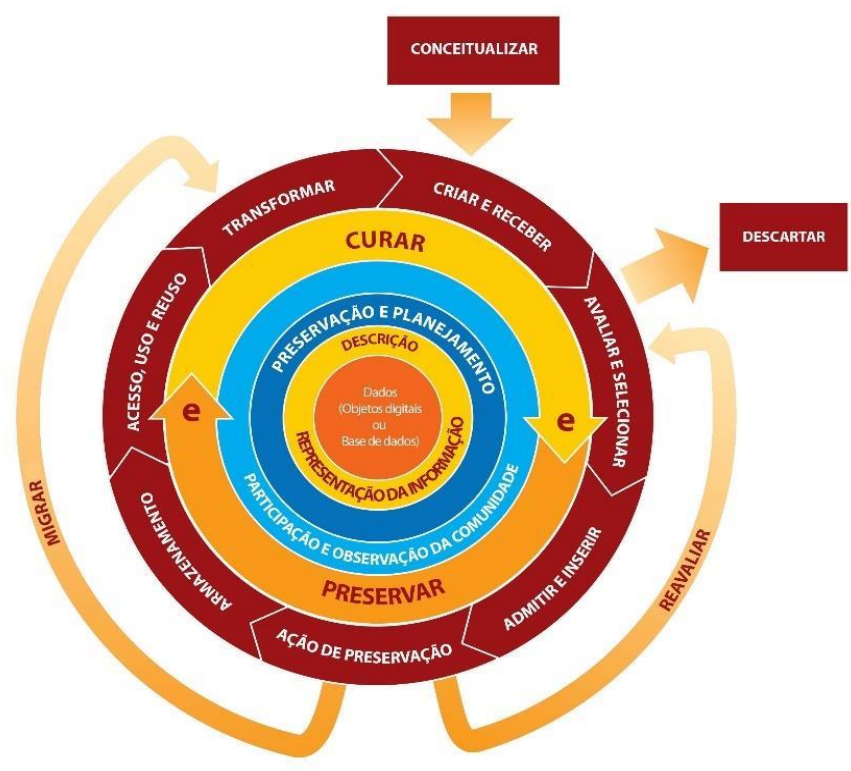

Fonte: Higgins $\left(2008^{1}\right)$

As ações macro da figura 1 são: descrição e representação de informação; preservação e planejamento; participação e observação da comunidade; preservar e curar. As ações micro são: criar e receber; avaliar e selecionar; admitir e inserir; ação de preservação; armazenamento; acesso, uso e reuso; e transformação. Também existem ações ocasionais: ordenação, reavaliação e migração. Essas ações atuam sobre as representações digitais a serem curadas. Entre as ações destacaram-se nessa pesquisa: a descrição e representação de informação e a preservação e planejamento.

$\mathrm{Na}$ ação de "descrição e representação de informação", a criação e a gestão de metadados são estabelecidos pelos curadores e catalogadores antes de seu registro. Segundo Higgins (2008), atribui-se, nessa fase, metadados administrativos, descritivos, técnicos, estruturais e de preservação, de acordo com padrões apropriados, que garantam a descrição e controle dos dados a longo prazo.

A ação "preservação e planejamento" consiste de um plano para a preservação em todo o ciclo de vida do objeto digital "que pode incluir o plano

\footnotetext{
1 Tradução autorizada de Natalia Nakano (2019, p. 82).
} 
para gestão e administração de todas as ações da curadoria" (HIGGINS, 2008, p. 137, tradução nossa). Na prática, a preservação é responsável por aceitar "ações que garantem a preservação no longo prazo e conserve a natureza autoritária dos dados. Essa deve garantir autenticidade, confiabilidade, integridade e usabilidade" (HIGGINS, 2011, p. 138, tradução nossa).

Sistemas baseados no modelo OAIS e outros padrões internacionais voltados ao gerenciamento e preservação da informação devem assegurar a autenticidade, confiabilidade, integridade e usabilidade aos objetos digitais. No contexto arquivístico, refere-se a repositórios digitais confiáveis para documentos arquivísticos digitais. De acordo com o Conarq: "Um repositório digital deve preservá-los e prover acesso a eles pelo tempo necessário". (2015, p. 9).

Lampert (2016) recomenda o Archivematica para preservação digital dos objetos digitais por ser um software completo: "o Archivematica tem como principal característica a preservação digital com base nas estratégias de emulação, migração e normalização, e se destaca pela geração de pacotes de informação para admissão, acesso e arquivamento segundo o modelo OAIS" (LAMPERT, 2016, p. 152). O Archivematica é utilizado pelo The Museum of Modern Art (MOMA) na preservação digital de seus acervos.

Higgins (2008, p. 135, tradução nossa) menciona que o Modelo OAIS é para a construção de sistema:

O design do fluxo de trabalho, gestão de problemas, identificação de processos e uso das boas práticas pode tudo ser encontrado através de aplicações de padrões, tais como OAIS (International Organization for Standardization [ISO], 2003) e ISO 15489 (ISO, 2001).

Esse modelo é indicado para o desenvolvimento de sistemas digitais e repositórios devido à facilitação do intercâmbio de dados e a interoperabilidade entre sistemas. Quanto a ação "descrição e representação da informação", os metadados administrativos, descritivos, estruturais, técnicos e de preservação, documentam a criação, proveniência e outros dados importantes no ciclo de vida dos objetos digitais.

No ambiente digital, amplia-se a importância dos metadados que, além de representar a informação, facilitar o acesso, o intercâmbio entre sistemas e a 
interoperabilidade técnica e semântica, apresentam-se como solução para o problema de preservação a partir da "identificação de um conjunto de dados e informações, expressos na forma de metadados, que ancorem os processos de gestão da preservação digital" (SAYÃO, 2010, p. 3). Nesse sentido, os metadados administrativos, descritivos, estruturais, técnicos e de preservação são contemplados por softwares e sistemas digitais que realizam a CD e facilitam o trabalho dos curadores, tais como o AtoM e o Archivematica, que descrevem, representam e propiciam o acesso e preservação à herança cultural a longo prazo.

O Archivematica é um sistema de preservação digital que, para acessar as representações digitais, necessita ser convergido com ○ AtoM, ambos gratuitos, criados pela Artefactual System. Tratam-se de softwares livres e de código aberto, sob licenças Affero General Public License (GNU) que oferecem a liberdade para estudar, modificar, melhorar e distribuir versões modificadas. Além disso, esses softwares se encontram em beta perpétuo, o que significa estarem em constante atualização e melhoramento por meio do feedback da comunidade utilizadora, o que garante a eficiência no processo de curadoria e preservação digital.

O Archivematica é um conjunto integrado de ferramentas de software de código aberto que permite que os usuários processem objetos digitais desde 0 ingresso até o acesso e se encontra em conformidade com o modelo funcional ISO-OAIS. Além da utilização desse modelo, o Archivematica baseia-se em normas, padrões e esquemas - tais como METS, PREMIS, Dublin Core, a especificação Baglt da Library of Congress, entre outras normas reconhecidas para gerar pacotes de arquivamento confiáveis, autênticos, seguros e independentes (ARCHIVEMATICA, 2021).

Por sua vez, o AtoM é um software de descrição e de representação arquivística, baseado nas normas internacionais de Arquivologia, desenvolvidas pelo Conselho Internacional de Arquivo (ICA). Esse sistema é multilíngue, multirepositório, customizável, interoperável e permite a importação e exportação em Dublin Core, EAD, SKOS, EAC-CPF, com seu acesso via Web. O AtoM, ao convergir com o Archivematica, transforma-se em um compósito de 
repositório digital.

A descrição do acervo arquivístico no AtoM leva em conta as seguintes normas: ISAD(G) de 2000, com 26 elementos descritivos de objetos; ISAAR (CPF) de 2004, com 31 elementos descritivos para entidades (físicas ou jurídicas); ISDHIA, de 2008, com 32 elementos descritivos para instituição custodiadora; ISDF de 2007, com 22 elementos descritivos para funções administrativas. Outros padrões de metadados também podem ser utilizados para a descrição do objeto, tais como a RAD (com 61 elementos), DACs (com 39 elementos), a MODS (com 16 elementos) e o Esquema Dublin Core (com 15 elementos). As informações são organizadas por área descritivas que se desdobram em elementos de descrição - os metadados.

\section{REPRESENTAÇÃO MUSEOLÓGICA}

A preocupação da normalização documental museográfica iniciou-se no século XIX com a necessidade da gestão nos museus. Contudo, o estudo da padronização e uniformidade ganhou força somente no século $X X$, nas associações nacionais de museus, referente aos instrumentos de pesquisa guias, catálogos e inventários.

Em 1950 criou-se um Comitê Internacional de Documentação no ICOM, o CIDOC, que, desde então, trabalha para a normalização documental e a informatização adequada nos museus, ao difundir ideias concernentes ao âmbito documental nas instituições museológicas. O CIDOC busca concentrar-se nas necessidades dos museus no contexto de diferentes especialidades e no estabelecimento de grupos categóricos para descrição de objetos (MARíN TORRES, 2002).

Nos anos de 1970 começou-se a pensar em um tipo de uniformidade documental, com a fundação da organização nacional Information Retrieval Group of the Museum Association (IRGMA), dentro da Associação de Museus, no Reino Unido - voltado à recuperação da informação e aos problemas e soluções derivados do surgimento de sistemas tecnológicos eletrônicos (MARÍN TORRES, 2002).

Em 1978, em uma reunião em Julita (Suécia), o CIDOC iniciou discussões 
sobre um conjunto de categorias de informações para objetos museológicos. Robert G. Chenhall e Peter Homulos apresentaram 16 categorias destinadas a identificar o objeto, bem como realizar o registro histórico e informações para uso em inventários (CIDOC, 1995). No período de 1980 a 1992 houve duas iniciativas do CIDOC:

[...] um Grupo de Trabalho Padrão de Dados que desenvolveu categorias de informação para coleções de arte e de arqueologia (Conselho Internacional de Museus, Comité Internacional de Documentação, 1992 e 1993) e um Grupo de Trabalho de Modelo de Dados que projetou um modelo de dados de informação do museu (Conselho Internacional de Museus). (CIDOC, 1995, tradução nossa).

Em 1992, o CIDOC analisou o progresso destas iniciativas e identificou a necessidade de consolidação do trabalho anterior em boas práticas acessíveis e disponíveis. De 1993 a 1995 o Comitê voltou-se ao desenvolvimento de Diretrizes Internacionais para informação de objetos museológicos. Em 1995, a primeira edição das Diretrizes Internacionais de informação sobre objetos de Museus foi apresentada durante a Conferência Trienal do ICOM de 1995, em Stavanger. Essas diretrizes foram "elaboradas a partir da experiência de profissionais de várias regiões do mundo, mas principalmente dos Estados Unidos, Canada, França e Reino Unido" (DECLARAÇÃO DOS PRINCÍPIOS..., 2014, p. 12). Destacou-se a distribuição das cópias dessas diretrizes para estimular sua aplicação e desenvolvimento, voltado a aumentar o consenso sobre o conteúdo na conferência Trienal do ICOM de 1998 (CIDOC, 1995).

Segundo o CIDOC (1995) as Diretrizes voltam-se à descrição e registro sobre os objetos museológicos - base para o inventário e a catalogação completa do acervo - e "podem ser adotadas por museus individualmente, organizações nacionais de documentação ou desenvolvedores de sistemas como base para um sistema, em operação, de documentação para museus" (CIDOC, 1995, p. 19, tradução nossa).

As Diretrizes são compostas por 22 grupos: Informação sobre aquisição; Informação sobre estado de conservação; Informação sobre Baixa patrimonial e Alienação; Informação sobre descrição; Informação sobre Imagem; Informação sobre Instituição; Informação sobre Localização; Informação sobre Marca e Inscrição; Informação sobre Material e Técnica; Informação sobre Medição; 
Informação sobre Associação de Objeto; Informação sobre Coleta de Objeto; Informação sobre Registro de Objeto; Informação sobre Nome de Objeto; Informação sobre Número de Objeto; Informação sobre Produção de Objeto; Informação sobre Título de Objeto; Informação sobre Parte e Componente; Informação sobre catalogação; Informação sobre Referência; Informação sobre Direitos de Reprodução; Informação sobre Assunto Representado. Cada grupo desdobra-se em categorias (metadados) que descrevem os objetos.

As TIC trouxeram novas tendências e a necessidade de adaptação dos museus à nova realidade, tais como softwares de representações das informações digitais, que, progressivamente, deixaram de ser manuais para converter-se em sistemas de informação integrados e de maior complexidade. Para as transformações tornaram-se fundamentais ter como base as diretrizes, normas e modelos de representação de acervos museológicos e um trabalho interdisciplinar.

\section{ANÁLISE DAS DIRETRIZES E ATOM}

A Curadoria Digital (CD) da herança cultural é fundamental para a sua preservação e acesso à geração atual e futura, em ambientes digitais. $O$ Archivematica atende às necessidades do acervo museológico na preservação digital. Contudo, para o acesso às representações digitais dos objetos de museus preservados no Archivematica, necessita-se da convergência com o AtoM.

Nessa tela, foi realizada uma comparação entre os modelos descritivos do AtoM - que dispõem os modelos descritivos de todas as normas arquivísticas internacionais e algumas nacionais - e o modelo descritivo das Diretrizes de Informação para Museus do CIDOC de 1995, composta por 22 grupos e 74 categorias. Identificaram-se os metadados do AtoM que podem corresponder aos elementos das diretrizes do CIDOC, como mostra o quadro 1 : 
Quadro 1 - Elementos descritivos da Diretrizes do CIDOC e do AtoM

\begin{tabular}{|c|c|c|c|}
\hline \multicolumn{2}{|r|}{ CIDOC } & \multicolumn{2}{|c|}{ ATOM } \\
\hline $\begin{array}{c}\text { Áreas de } \\
\text { Informação no } \\
\text { CIDOC }\end{array}$ & Metadados CIDOC & Metadados ATOM & $\begin{array}{c}\text { Modelos } \\
\text { descritivos no } \\
\text { ATOM }\end{array}$ \\
\hline \multirow{3}{*}{$\begin{array}{l}1 \text { - Informação } \\
\text { de Aquisição }\end{array}$} & 1- Meio de aquisição & Tipo de aquisição & \multirow{6}{*}{$\begin{array}{l}\text { Modelo descritivo } \\
\text { de registro de } \\
\text { ingresso de } \\
\text { acervos }\end{array}$} \\
\hline & 2- Data da Aquisição & Data - Acumulação & \\
\hline & 3- Fonte de Aquisição & $\begin{array}{l}\text { Fonte imediata de } \\
\text { aquisição }\end{array}$ & \\
\hline \multirow{3}{*}{$\begin{array}{l}2 \text { - Informação } \\
\text { sobre a condição }\end{array}$} & 4- Condição & \multirow{2}{*}{ Condição física } & \\
\hline & 5- Resumo da condição & & \\
\hline & 6- Data da condição & Condição física & \\
\hline \multirow{4}{*}{$\begin{array}{l}3 \text { - Informação } \\
\text { de transferência } \\
\text { e eliminação }\end{array}$} & 7- Data da transferência & $\begin{array}{l}\text { Data do recurso } \\
\text { relacionado- data de } \\
\text { transferência }\end{array}$ & $\begin{array}{l}\text { Registro de } \\
\text { Transferência }\end{array}$ \\
\hline & 8- Data da eliminação & \multirow{3}{*}{$\begin{array}{l}\text { Avaliação, eliminação e } \\
\text { temporalidade }\end{array}$} & \multirow{3}{*}{$\operatorname{ISAD}(\mathrm{G})$} \\
\hline & 9- Método de eliminação & & \\
\hline & $\begin{array}{l}\text { 10-Destinatário de } \\
\text { eliminação }\end{array}$ & & \\
\hline \multirow{2}{*}{$\begin{array}{l}4 \text { - Informação } \\
\text { de descrição }\end{array}$} & 11- Descrição Física & Âmbito e Conteúdo & \multirow{2}{*}{$\operatorname{ISAD}(\mathrm{G})$} \\
\hline & 12- Status da amostra & Ponto de acesso & \\
\hline \multirow[t]{2}{*}{$\begin{array}{l}5 \text { - Informação } \\
\text { da Imagem }\end{array}$} & 13- Tipo de imagem & Metadados da imagem & $\begin{array}{c}\text { Campos } \\
\text { descritivos da } \\
\text { imagem }\end{array}$ \\
\hline & $\begin{array}{l}\text { 14- Número de referência } \\
\text { da imagem }\end{array}$ & Metadados da imagem & $\begin{array}{l}\text { Edição do objeto } \\
\text { digital }\end{array}$ \\
\hline 6 - Informacão & 15- Nome da instituição & $\begin{array}{l}\text { Forma autorizada do } \\
\text { nome }\end{array}$ & \multirow{4}{*}{ ISDIAH } \\
\hline da Instituição & $\begin{array}{l}\text { 16- Nome da subdivisão } \\
\text { da instituição }\end{array}$ & Estrutura administrativa & \\
\hline & $\begin{array}{l}\text { 17- Endereço da } \\
\text { Instituição }\end{array}$ & \multirow[t]{2}{*}{ Zona de contato } & \\
\hline & 18- País da Instituição & & \\
\hline \multirow{4}{*}{$\begin{array}{l}7 \text { - Informação } \\
\text { da localização }\end{array}$} & 19- Localização Atual & $\begin{array}{l}\text { Unidade de instalação } \\
\text { ou História do Arquivo }\end{array}$ & $\begin{array}{c}\text { Ligação ao } \\
\text { depósito físico } \\
\text { ou ISAD(G) }\end{array}$ \\
\hline & $\begin{array}{l}\text { 20- Tipo de localização } \\
\text { atual }\end{array}$ & História do Arquivo & \multirow{2}{*}{$\operatorname{ISAD(G)}$} \\
\hline & $\begin{array}{l}\text { 21- Data da localização } \\
\text { atual }\end{array}$ & História do Arquivo & \\
\hline & 22- Localização normal & Unidade de instalação & $\begin{array}{c}\text { Ligação ao } \\
\text { depósito físico }\end{array}$ \\
\hline \multirow{7}{*}{$\begin{array}{l}8 \text { - Informação } \\
\text { de inscrição e } \\
\text { marca }\end{array}$} & 23- Texto da inscrição/marca & \multirow{7}{*}{$\begin{array}{l}\text { Não possui campo } \\
\text { específico, mas nas } \\
\text { imagens das partes do } \\
\text { objeto, pode ser } \\
\text { descrito em âmbito e } \\
\text { conteúdo e âmbito ou } \\
\text { notas }\end{array}$} & \multirow{7}{*}{$\operatorname{ISAD(G)}$} \\
\hline & 24- Tipo de inscrição/marca & & \\
\hline & 25- Descrição de inscrição/marca & & \\
\hline & $\begin{array}{l}\text { 26- Técnica de inscrição de } \\
\text { inscrição/marca }\end{array}$ & & \\
\hline & 27- Posição de inscrição/marca & & \\
\hline & $\begin{array}{l}\begin{array}{l}\text { 28- Linguagem da } \\
\text { inscrição/marca }\end{array} \\
\end{array}$ & & \\
\hline & 29- Tradução da inscrição/marca & & \\
\hline
\end{tabular}




\begin{tabular}{|c|c|c|c|}
\hline \multirow[t]{3}{*}{$\begin{array}{l}9 \text { - Informação } \\
\text { de Material e } \\
\text { técnica }\end{array}$} & 30- Material & \begin{tabular}{|l} 
Dimensão e \\
suporte/âmbito e \\
conteúdo/ ponto de \\
acesso - (gênero)
\end{tabular} & \multirow[t]{3}{*}{$\operatorname{ISAD}(\mathrm{G})$} \\
\hline & 31- Técnica & \multirow[b]{2}{*}{ Âmbito e conteúdo } & \\
\hline & $\begin{array}{l}\text { 32- Descrição da parte ou } \\
\text { componente }\end{array}$ & & \\
\hline \multirow[t]{3}{*}{$\begin{array}{l}10 \text { - Informação } \\
\text { de medidas }\end{array}$} & \begin{tabular}{|l|} 
33- Dimensão \\
34- Medida \\
\end{tabular} & \multirow[t]{3}{*}{ Dimensão e suporte } & \multirow{3}{*}{$\operatorname{ISAD}(\mathrm{G})$} \\
\hline & 35- Medida Unitária & & \\
\hline & 36- Parte medida & & \\
\hline \multirow{5}{*}{$\begin{array}{l}11 \text { - Informação } \\
\text { de objeto } \\
\text { associado }\end{array}$} & 37- Lugar associado & $\begin{array}{l}\text { Ponto de acesso e } \\
\text { História do Arquivo }\end{array}$ & ISAD(G) \\
\hline & 38- Data associada & Data & $\operatorname{ISAD}(\mathrm{G})$ \\
\hline & $\begin{array}{l}\text { 39- Nome da } \\
\text { pessoa/grupo associado }\end{array}$ & Nome do produtor(s) & ISAAR (CPF) \\
\hline & 40- Tipo de associação & $\begin{array}{l}\text { Área de relacionamento } \\
\text { - recursos } \\
\text { relacionados/natureza da } \\
\text { relação e ponto de } \\
\text { acesso/ocupação } \\
\end{array}$ & ISAAR (CPF) \\
\hline & 41- Função original & Âmbito e Conteúdo & $\operatorname{ISAD}(\mathrm{G})$ \\
\hline \multirow{4}{*}{$\begin{array}{l}12 \text { - Informação } \\
\text { da coleta dos } \\
\text { objetos }\end{array}$} & 42- Lugar da coleta & $\begin{array}{l}\text { Ponto de acesso e } \\
\text { História do Arquivo }\end{array}$ & ISAD(G) \\
\hline & 43- Data da coleta & Data & $\operatorname{ISAD}(\mathrm{G})$ \\
\hline & 44- Coletor & $\begin{array}{l}\text { Nome do Produtor - } \\
\text { ponto de } \\
\text { acesso/ocupação } \\
\text { seguido da } \\
\text { especificação em notas } \\
\text { nome do objeto. } \\
\end{array}$ & ISAAR (CPF) \\
\hline & 45- Método de coleta & Âmbito e Conteúdo & $\operatorname{ISAD}(\mathrm{G})$ \\
\hline \multirow{5}{*}{$\begin{array}{l}13 \text { - Informação } \\
\text { da entrada do } \\
\text { objeto }\end{array}$} & 46- Proprietário atual & $\begin{array}{l}\text { Nome do Produtor - } \\
\text { ponto de } \\
\text { acesso/ocupação } \\
\text { seguido da } \\
\text { especificação em notas } \\
\text { nome do objeto. } \\
\end{array}$ & ISAAR (CPF) \\
\hline & 47- Depositante & Procedência & $\operatorname{ISAD}(\mathrm{G})$ \\
\hline & 48- Data de entrada & Data de Aquisição & \multirow{2}{*}{$\begin{array}{c}\text { Modelo descritivo } \\
\text { de registro de } \\
\text { ingresso de } \\
\text { acervos }\end{array}$} \\
\hline & 49- Número de entrada & Número de incorporação & \\
\hline & 50- Razão de entrada & $\begin{array}{l}\text { Avaliação, seleção e } \\
\text { eliminação - Área de } \\
\text { Conteúdo e Âmbito }\end{array}$ & $\operatorname{ISAD(G)}$ \\
\hline \multirow{2}{*}{$\begin{array}{l}14 \text { - Informação } \\
\text { do nome do } \\
\text { objeto }\end{array}$} & 51- Nome do objeto & Título & \multirow[b]{2}{*}{$\operatorname{ISAD(G)}$} \\
\hline & $\begin{array}{l}\text { 52- Tipo de nome do } \\
\text { objeto }\end{array}$ & Notas - Área de notas & \\
\hline
\end{tabular}




\begin{tabular}{|c|c|c|c|}
\hline & $\begin{array}{l}\text { 53- Autoridade do nome } \\
\text { do objeto }\end{array}$ & $\begin{array}{l}\text { Nome do Produtor - } \\
\text { ponto de } \\
\text { acesso/ocupação } \\
\text { seguido da } \\
\text { especificação em notas } \\
\text { nome do objeto. Ou } \\
\text { Notas } \\
\end{array}$ & $\begin{array}{l}\text { ISAAR (CPF) } \\
\text { ou ISAD(G) }\end{array}$ \\
\hline \multirow{3}{*}{$\begin{array}{l}15 \text { - Informação } \\
\text { do número do } \\
\text { objeto }\end{array}$} & 54- Número do objeto & Código de referência & \multirow{3}{*}{$\operatorname{ISAD}(\mathrm{G})$} \\
\hline & $\begin{array}{l}\text { 55- Tipo de número do } \\
\text { objeto }\end{array}$ & \begin{tabular}{|l|} 
Identificadores \\
alternativos
\end{tabular} & \\
\hline & $\begin{array}{l}\text { 56- Data do número do } \\
\text { objeto }\end{array}$ & \begin{tabular}{|l|} 
Identificadores \\
alternativos - na \\
etiqueta: tipo de \\
número seguido da \\
data
\end{tabular} & \\
\hline \multirow{4}{*}{$\begin{array}{l}16 \text { - Informação } \\
\text { da Produção do } \\
\text { objeto }\end{array}$} & 57- Lugar de Produção & Ponto de acesso- Lugar & $\begin{array}{l}\text { modelo descritivo } \\
\text { da ISAD }(G)\end{array}$ \\
\hline & 58- Data de Produção & Data & $\operatorname{ISAD}(\mathrm{G})$ \\
\hline & $\begin{array}{l}\text { 59- Nome da } \\
\text { pessoa/grupo de produção }\end{array}$ & Nome de produtor(s) & ISAAR (CPF) \\
\hline & 60- Regras de produção & $\begin{array}{l}\text { Pode ser contemplado } \\
\text { em âmbito e conteúdo }\end{array}$ & $\operatorname{ISAD}(\mathrm{G})$ \\
\hline \multirow{3}{*}{$\begin{array}{l}17 \text { - Informação } \\
\text { do Título do } \\
\text { Objeto }\end{array}$} & 61- Título & Título & \multirow[t]{3}{*}{$\operatorname{ISAD}(\mathrm{G})$} \\
\hline & 62- Tipo de título & $\begin{array}{l}\text { pode ser inserido nas } \\
\text { notas }\end{array}$ & \\
\hline & 63- Tradução do título & Área de nota & \\
\hline \multirow{2}{*}{$\begin{array}{l}18 \text { - Informação } \\
\text { do componente e } \\
\text { parte }\end{array}$} & $\begin{array}{l}\text { 64- Número de partes ou } \\
\text { componentes }\end{array}$ & Código de referência & \multirow{2}{*}{$\operatorname{ISAD}(\mathrm{G})$} \\
\hline & $\begin{array}{l}\text { 65- Descrição de partes e } \\
\text { componentes }\end{array}$ & Âmbito e Conteúdo & \\
\hline \multirow{3}{*}{$\begin{array}{l}19 \text { - Informação } \\
\text { de Registro }\end{array}$} & 66- Arquivista & Nota do arquivista & \multirow{3}{*}{$\operatorname{ISAD}(\mathrm{G})$} \\
\hline & 67- Data do Registro & $\begin{array}{l}\text { Datas de criação, revisão } \\
\text { ou eliminação }\end{array}$ & \\
\hline & 68- Autoridade & Fontes & \\
\hline $\begin{array}{l}20 \text { - Informação } \\
\text { de Referência }\end{array}$ & \begin{tabular}{|l|} 
69- Referência \\
70- Tipo de referência \\
\end{tabular} & $\begin{array}{l}\text { Zona de Documentação } \\
\text { Associada }\end{array}$ & $\operatorname{ISAD}(\mathrm{G})$ \\
\hline \multirow{2}{*}{$\begin{array}{l}21 \text { - Informação } \\
\text { de Direitos de } \\
\text { reprodução }\end{array}$} & $\begin{array}{l}\text { 71- Nota de direito de } \\
\text { Reprodução }\end{array}$ & $\begin{array}{l}\text { Condições de acesso e } \\
\text { uso }\end{array}$ & $\operatorname{ISAD}(\mathrm{G})$ \\
\hline & $\begin{array}{l}\text { 72- Proprietário do direito } \\
\text { da reprodução }\end{array}$ & Proprietário dos direitos & $\begin{array}{l}\text { Modelo descritivo } \\
\text { Gestão de } \\
\text { direitos }\end{array}$ \\
\hline \multirow{2}{*}{$\begin{array}{l}22 \text { - Informação } \\
\text { resumida do } \\
\text { assunto- uso } \\
\text { controlado de } \\
\text { termos }\end{array}$} & 73- Assunto representado & Ponto de acesso & \multirow[b]{2}{*}{$\operatorname{ISAD}(\mathrm{G})$} \\
\hline & $\begin{array}{l}\text { 74- Descrição do assunto } \\
\text { representado }\end{array}$ & Âmbito e Conteúdo & \\
\hline
\end{tabular}

Fonte: Adaptada de Batista (2018).

Após a identificação e análise das categorias não atendidas, destacadas no quadro 1 , propôs-se uma customização na utilização dos metadados descritivos do AtoM, a partir de princípios do Design da Informação (DI), o que 
contribuiu para a CD e para a descrição das representações digitais de objetos em museus. No trabalho de customização, as categorias das Diretrizes de Informações do CIDOC foram atendidas da seguinte forma:

A "data da condição do objeto" (grupo 2) pode ser respondida juntamente no metadado "condição física", presente na área administrativa do modelo descritivo de registro de ingresso de acervos do AtoM, como mostra a Figura 2.

\section{Figura 2 - Registro de Ingresso - Zona Administrativa}

\section{Condiçă fisica}

Uma descriçăo da condiçăo fisica do ingresso e da necessidade de preservaçăo ou manuseamento.

Fonte: AtoM (2021a).

No modelo descritivo da $\operatorname{ISAD}(G)$, a "data da condição" pode ser informada no metadado "características físicas e requisitos técnicos", pertencente à área de condições de acesso e uso (figura 3).

Figura 3 - Área de Condições de acesso e uso da ISAD(G) no AtoM

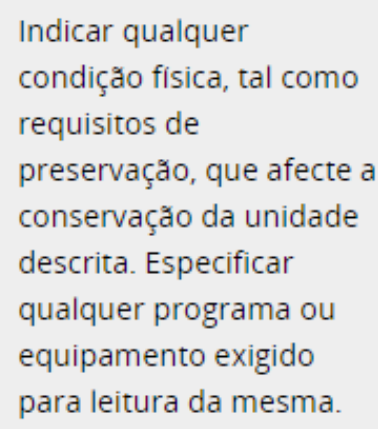

Características fisicas e requisitos técnicos

Instrumentos de descrição

Fonte: AtoM (2021b).

As informações sobre "localização atual", "tipo de localização" e "data da localização atual" (grupo 7) são atendidas tanto nos metadados "História do Arquivo" como em notas da $\operatorname{ISAD}(G)$, o primeiro presente na área de contextualização e o segundo na área de notas, apresentados na figura 4. 
Figura 4 - Área de Contextualização e área de notas da ISAD(G) no AtoM
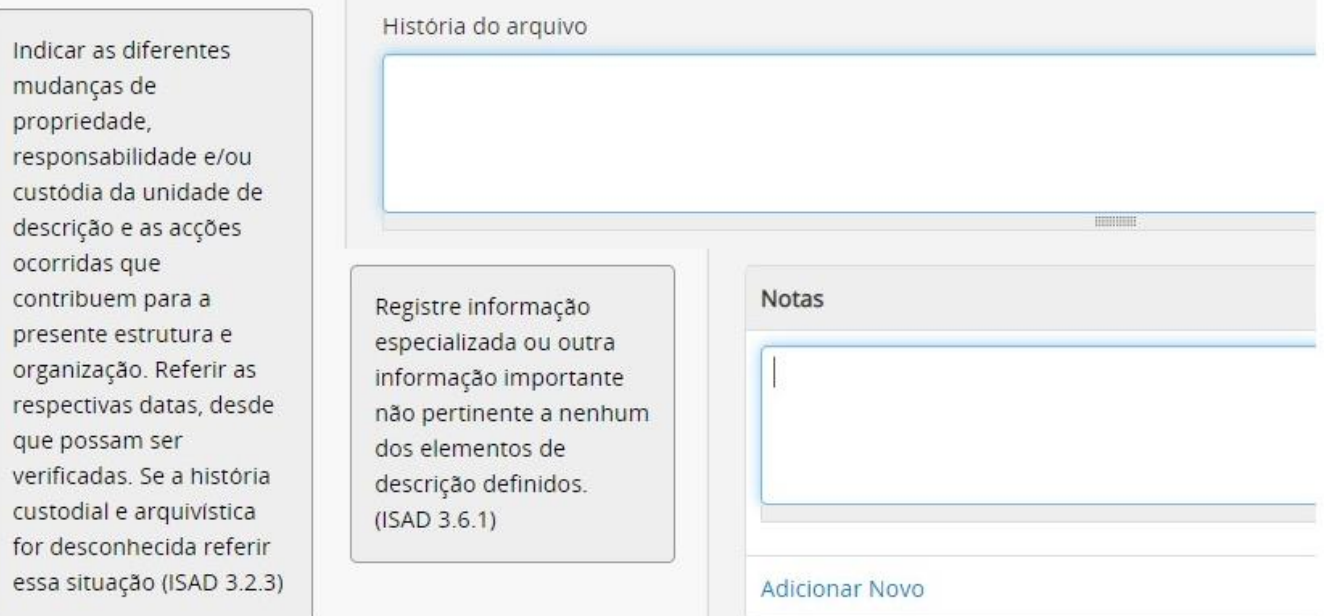

Fonte: AtoM (2021b).

Contudo, se a localização atual do objeto for na reserva técnica, cria-se o vínculo da representação digital com o depósito físico, no modelo descritivo de "Ligação a Objeto Físico", especificando-se o local exato do objeto dentro da reserva técnica.

A figura 5 apresenta a forma como se conecta um fundo, coleção ou item digital ao local de armazenamento (à direita) e os metadados referentes à instalação física (à esquerda).

Figura 5 - Vínculo da representação digital ao local físico do objeto

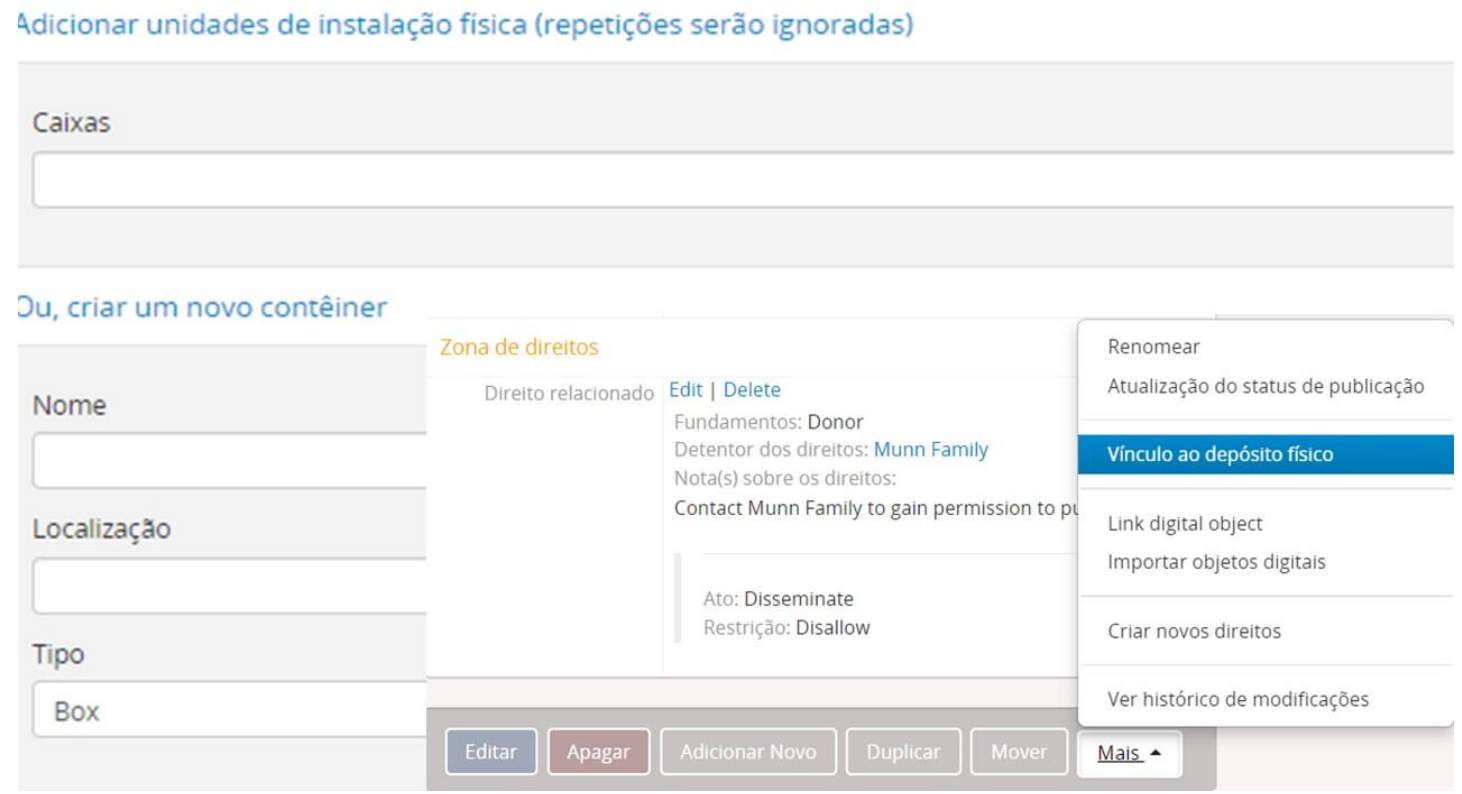

Fonte: AtoM (2021c). 
Informações referentes à "inscrições e marcas" (grupo 8) podem ser inseridas em "âmbito e conteúdo", presente na área de conteúdo e estrutura da ISAD(G), uma vez que, o AtoM permite a inserção de múltiplas facetas do objeto na sua representação digital, ou seja, a imagem das partes do objeto, como mostra a figura 6 .

Figura 6 - Bule de ágata

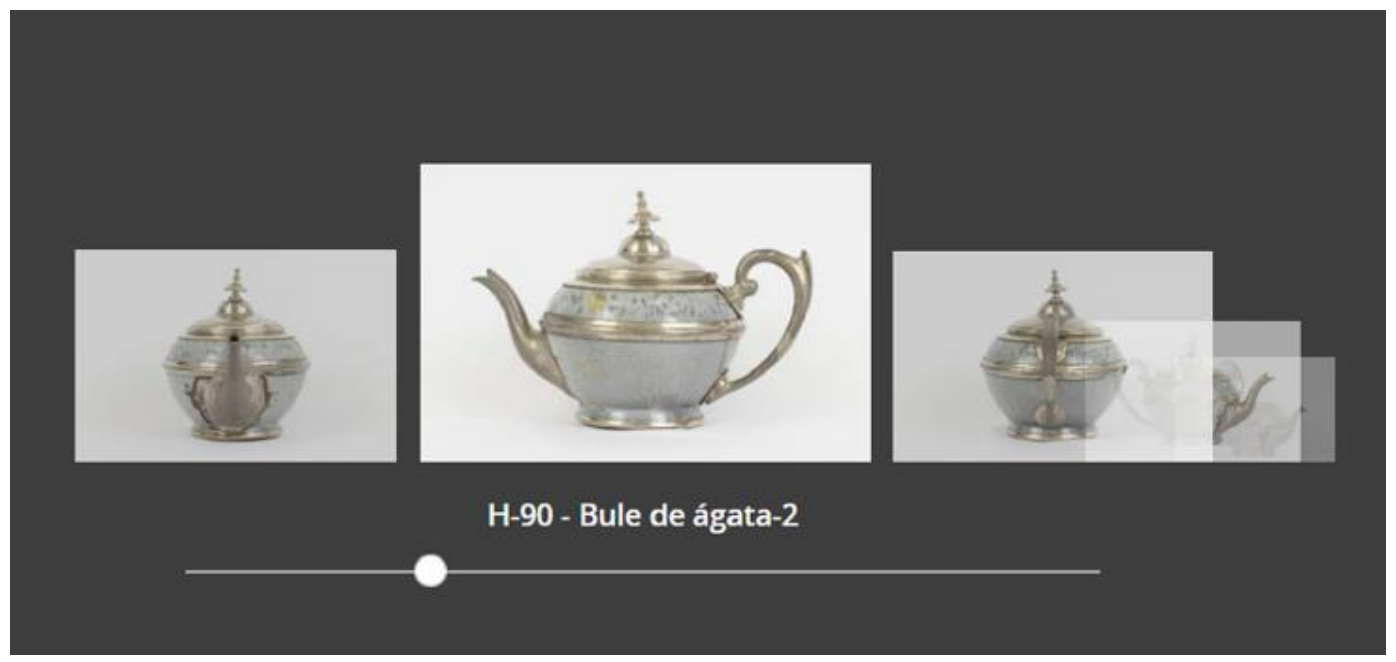

Fonte: Ladri (2019, p. 96).

Cada imagem na figura 6 é uma descrição do bule em nível de parte - um subitem do item -, o que favorece uma descrição mais detalhada de cada lado do objeto e a inserção da informação sobre a presença de inscrição ou marca em uma determinada faceta do objeto.

O "lugar associado" (grupo 11) pode estar presente nos "pontos de acesso" como mostra na figura 7 e também na "história do arquivo" (figura 4), se descrito em nível de item no AtoM.

Figura 7 - Ponto de Acesso no modelo descritivo do objeto no AtoM Pontos de acesso

Pontos de acesso de assunto

Pontos de acesso local

Pontos de acesso de genero

Pontos de acesso (assuntos)

Fonte: AtoM (2021b). 
Os dados de "lugar da coleta" (grupo 12) podem ser inseridos nos metadados "história do arquivo" da área de contextualização (figura 4) e "ponto de acesso" para lugar da $\operatorname{ISAD}(G)$ - exposto na figura 7. Para informação sobre o "coletor" utilizam-se os metadados "nome do produtor", os "pontos de acesso/ocupação" e "notas", localizados na área de identificação e pontos de acesso da ISAAR(CPF), especificam-se os nomes dos objetos coletados por uma determinada pessoa; da mesma forma, acontece com a informação do "proprietário atual" (grupo 13), como mostra a figura 8.

Figura 8 - Ponto de Acesso de autoridade do AtoM

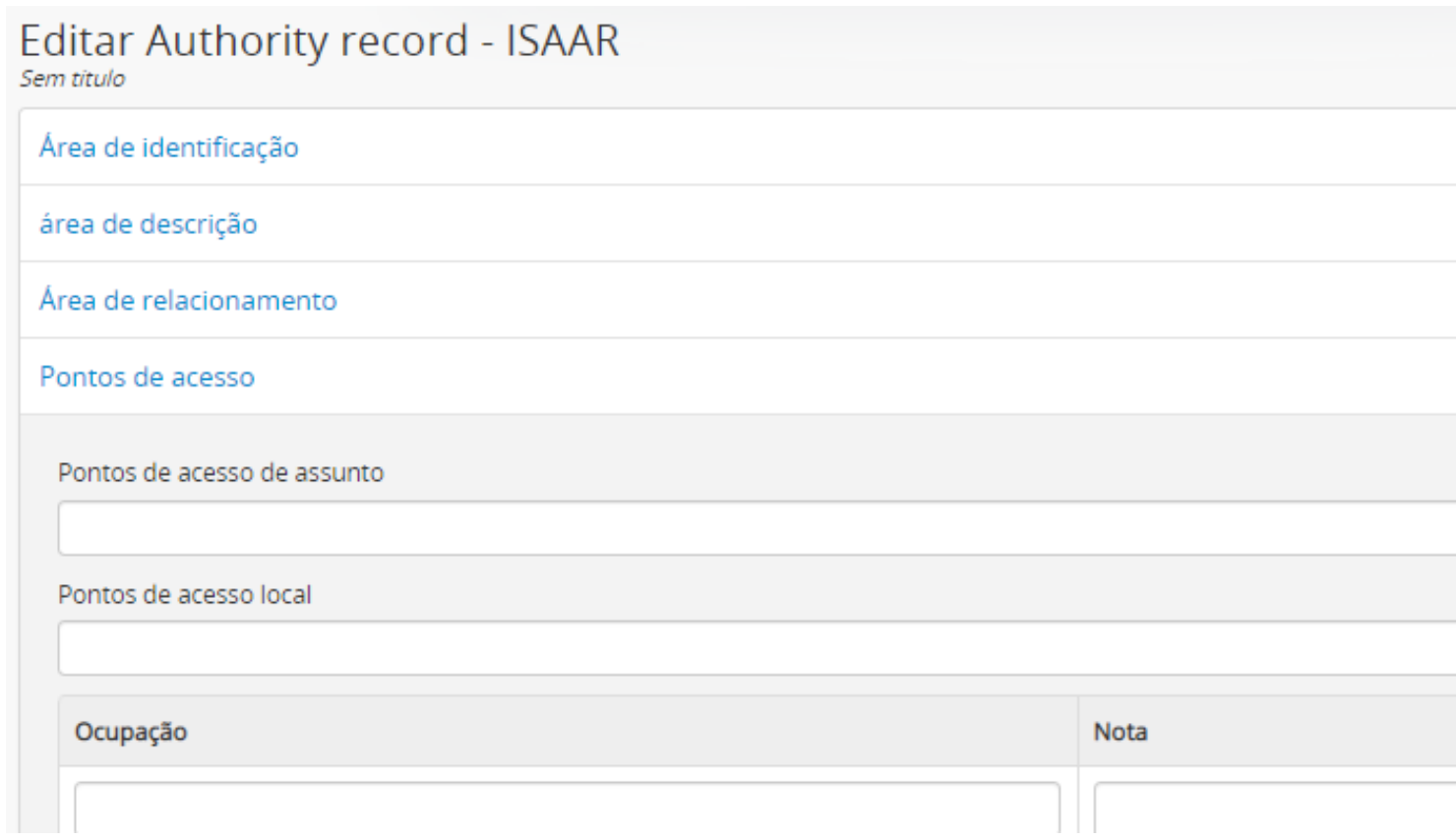

Fonte: AtoM (2021d).

Ressalta-se que, nas normas ISAD(G), ISAAR(CPF), ISDF e ISDHIA não há pontos de acesso (figuras 7 e 8), sendo adicionados pelos desenvolvedores do AtoM, pois são fundamentais na construção de vocabulário controlado, na busca e recuperação da informação. Destaca-se, também, que o metadado "ocupação", na figura 8 , pode ser adicionado mais de uma vez com sua respectiva nota.

Já "a razão de entrada" (grupo 13) pode ser inserida no metadado "avaliação, seleção e eliminação" (figura 9), situado na área conteúdo e estrutura do modelo descritivo da $\operatorname{ISAD}(G)$. 
Figura 9 - Área de conteúdo e estrutura da ISAD(G) no AtoM

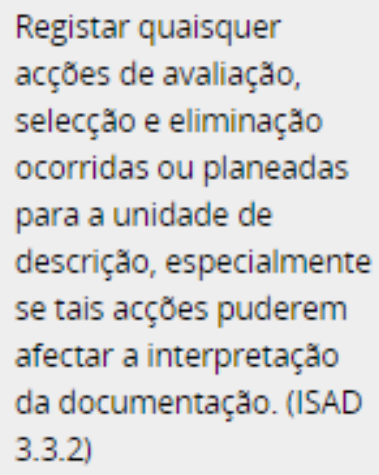

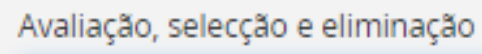

Fonte: AtoM (2021b).

Informações referentes ao "tipo de nome do objeto" (grupo 14) podem ser atendidas na "área de notas" (figura 4); e para "autoridade do nome do objeto" (grupo 14) descreve-se de acordo com o procedimento realizado nas informações sobre o "coletor e proprietário" (figura 8). A informação é também passível de ser inserida nas "notas", juntamente com o "tipo de nome do objeto".

A "data do número do objeto" (grupo 15) e inserida nos "identificadores alternativos", entre parênteses, depois do tipo de etiqueta - e encontra-se na área de identificação do AtoM, como exemplificado na figura 10.

Figura 10 - Identificador alternativo no AtoM

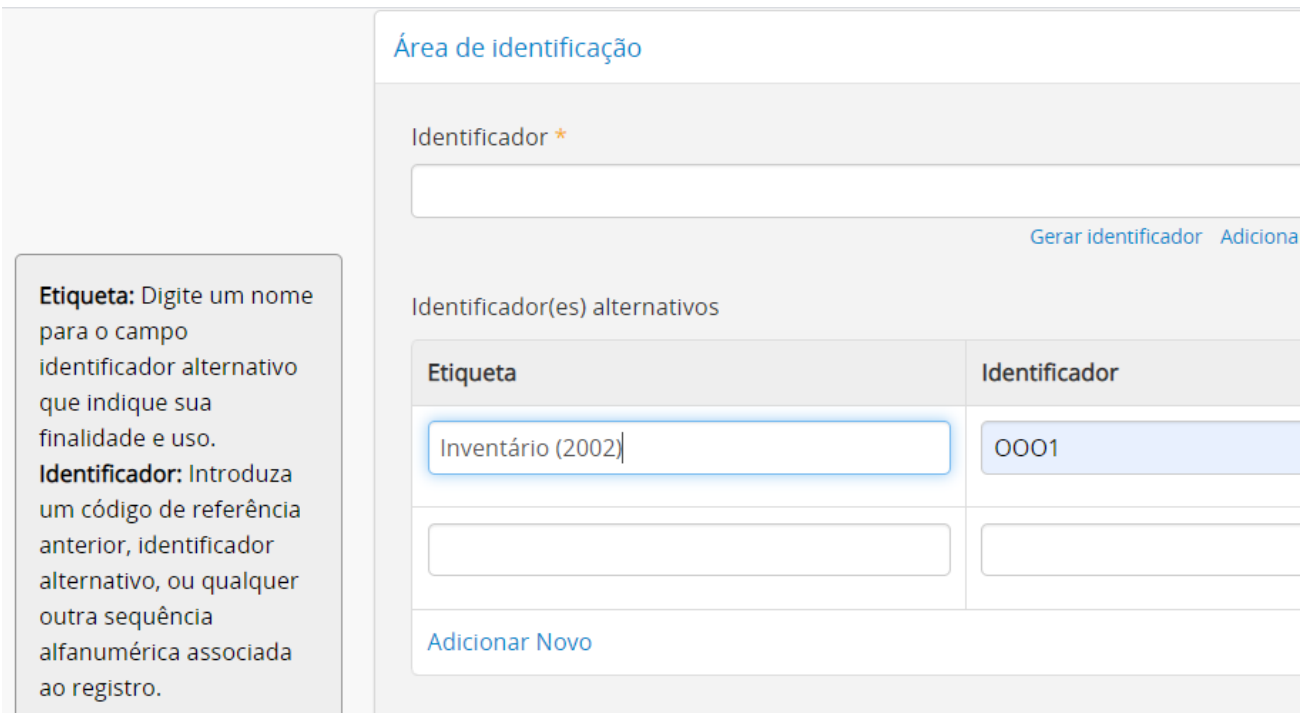

Fonte: AtoM (2021b). 
As informações sobre "regras de produção" (grupo 16) podem ser contempladas no metadado "âmbito e conteúdo" ao descrever o objeto museológico (figura 11).

\section{Figura 11 - Metadado Âmbito e Conteúdo da ISAD(G) no AtoM}

Indicar, de acordo com o
nível de descrição, um
sumário do âmbito (tais
como cronológico e
geográfico) e um resumo
do conteúdo (tais como
tipos de documentos,
assuntos, procedimentos
administrativos) da
unidade de descrição.
(ISAD 3.3.1)

Área de conteúdo e estrutura

Âmbito e conteúdo

Avaliação, selecção e eliminação

Fonte: AtoM (2021b).

Esse metadado pode utilizado para uma descrição ampla se em nível de fundo ou coleção ou para uma descrição detalhada quando em nível de item ou parte. Por fim, sobre o "tipo de título" (grupo 17), este deve ser inserido nas "notas" (figura 4) na área de notas da ISAD(G).

Destaca-se que existem metadados presentes no AtoM que não fazem parte das normas arquivísticas internacionais, devido à necessidade de atender às demandas da prática arquivística, de tornar-se um sistema flexível, bem como de ser um sistema com múltiplas funções, dentre as quais estão a gestão, controle, padronização, representação e acesso da informação.

A otimização na utilização dos metadados descritivos do AtoM de acordo com as Diretrizes de Informações do CIDOC contribuiu para CD do acervo museológico da Faculdade de Filosofia e Ciências, processo descrito no livro "Acervo Revisitado: intersecções e convergências no redesign de uma coleção díspare"2 publicado em 2019, com segunda edição, em 2020, disponível eletronicamente e em formato impresso.

\footnotetext{
2 Disponível em: https://ebooks.marilia.unesp.br/index.php/lab_editorial/catalog. Acesso em: 25 jul. 2021.
} 


\section{CONSIDERAÇÕES FINAIS}

A Ciência da Informação propõe um espaço de diálogo entre Arquivologia, Biblioteconomia e a Museologia, respeitando as suas especificidades. Compreende-se, por meio da literatura, que as três áreas dialogam, principalmente na representação da informação em ambientes digitais. Há, na prática, um movimento mundial na convergência entre as três áreas para a facilitação do acesso à informação, ao conhecimento e à sua socialização e democratização por meio de simulacros nos ambientes digitais.

A presença de representações de acervos museológicos em ambientes digitais necessita que tais representações passem pelo processo de Curadoria Digital, para garantir o acesso e a preservação a longo prazo às comunidades de interesse no presente e no futuro. Nesse sentido, propôs-se a utilização dos softwares Archivematica e AtoM convergidos para esse processo para criar representações digitais da herança cultural dos museus.

No contexto do acervo museológico da Faculdade de Filosofia e Ciências (FFC) da Unesp, o AtoM possibilitou o registro informacional referente aos objetos, de forma eficiente, ao considerar as limitações existentes na instituição, tais quais a situação do acervo e a falta de recursos para os trabalhos necessários à sua preservação e acesso.

O sistema representou o acervo histórico de maneira satisfatória e apresentou funcionalidades que facilitam a adaptação de certos problemas emergentes. Também, proporciona a inserção de outros metadados, que contribuem para o enriquecimento da metainformação do objeto museológico nos ambientes digitais.

Por outro lado, a implementação dos sistemas AtoM e Archivematica demonstrou a exigência de relações interdisciplinares com profissionais da Ciência da Computação, pois para a instalação e o bom desempenho dos sistemas são necessárias não somente competências arquivísticas como também tecnológicas, o que torna fundamental o diálogo multidisciplinar entre as duas áreas de profissionais especializados.

A pesquisa cujos resultados ora encaminhamos ao mesmo tempo em que 
apresenta uma resposta a questão formulada inicialmente, verificou a emergência da necessidade de mais aprofundamentos nas normas museológicas que possam contribuir para uma possível customização do AtoM, capaz de atender às necessidades mais complexas das instituições museológicas e favorecer a democratização e acesso à herança cultural, em ambos os ambientes, físicos e digitais as gerações presente e futura.

\section{REFERÊNCIAS}

ARCHIVEMATICA. Home, 2021. Disponível em: https://www.archivematica.org/pt-br/. Acesso em: 25 jul. 2021.

ATOM. Metadados do depósito físico, 2021c. Disponível em: https://demo.accesstomemory.org/kathleen-munnfonds/object/editPhysicalObjects. Acesso em: 25 jul. 2021.

ATOM. Modelo descrito da ISAD(G) no AtoM, 2021b. Disponível: https://demo.accesstomemory.org/informationobject/add. Acesso em: 25 jul. 2021.

ATOM. Ponto de Acesso de autoridade no AtoM, 2021d. Disponível em: https://demo.accesstomemory.org/actor/add. Acesso em: 25 jul. 2021.

ATOM. Registro de ingresso, 2021a. Disponível em: https://demo.accesstomemory.org/accession/add. Acesso em: 25 jul. 2021.

BATISTA, L. 2018. O redesign do sistema Access to Memory (AtoM) para a curadoria digital de acervos museológicos heterogêneos. Dissertação (Mestrado em Ciência da Informação) - Faculdade de Filosofia e Ciências, Universidade Estadula Paulista, Marília, 2018. Disponível em: http://hdl.handle.net/11449/154326. Acesso em: 25 jul. 2021.

CIDOC - INTERNATIONAL DOCUMENTATION COMMITTEE. International guidelines for museum object information: the CIDOC information categories. Berlin: ICOM, 1995. Disponível em: http://cidoc.mini.icom.museum/wpcontent/uploads/sites/6/2018/12/guidelines1995.pdf. Acesso em: 25 jul. 2021.

CONSELHO NACIONAL DE ARQUIVOS (CONARQ). Diretrizes para a implementação de repositórios arquivisticos digitais confiáveis - RDCArq. Rio de Janeiro, 2015. Disponível em: https://www.gov.br/conarq/pt$\mathrm{br} /$ centrais-de-

conteudo/publicacoes/conarq_diretrizes_rdc_arq_resolucao_43.pdf. Acesso em: 25 jul. 2021. 


\section{DECLARAÇÃO DOS PRINCÍPIOS de documentação em museus e} Diretrizes internacionais de informação sobre objetos: categorias de informação do CIDOC / Comitê Internacional de Documentação (CIDOC). São Paulo: Associação de Amigos do Museu do Café; Pinacoteca do Estado de São Paulo, 2014.

DÍAZ BALERDI, I. La memoria fragmentada: el museo y sus paradojas. Espanha: Ediciones Trea, 2008.

DIGITAL CURATION CENTRE (DCC). What is Curator. Edinburgh, 2004. Disponível em: https://www.dcc.ac.uk/about/digital-curation. Acesso em: 25 jul. 2021.

HIGGINS, S. Digital Curation: the emergence of a new discipline. The International Journal of Digital Curation, v. 6, n. 2, p. 78-88, 2011. Disponível em: http://www.ijdc.net/article/view/184/251. Acesso em: 25 jul. 2021.

HIGGINS, S. The DCC Curation Lifecycle Model. The International Journal of Digital Curation, v. 3, n. 1, p. 134-140, 2008. Disponível: http://www.ijdc.net/article/view/184/. Acesso em: 25 jul. 2021.

LADRI. Acervo revisitado: intersecções e convergências no redesign de uma coleção díspare. Marília, 2019. Disponível em:

https://newsstand.joomag.com/pt-BR/acervo-revisitado/0519703001576182534. Acesso em: 25 jul. 2021.

LAMPERT, S. R. Os repositórios DSpace e archivematica para documentos arquivísticos digitais. Acervo, Rio de Janeiro, v. 29, n. 2, p. 143-154, jul./dez. 2016. Disponível em:

http://revista.arquivonacional.gov.br/index.php/revistaacervo/article/view/718. Acesso em: 25 jul. 2021.

MARÍN TORRES, M. T. Historia de la documentación museológica: la gestión de la memoria artística. Gijón/Asturias: Trea, 2002.

SABHARWAL, A. Digital curation in the digital humanities: preserving and promoting archival and special collections. Waltham: Elsevier, 2015.

SAYÃO, L. F. Uma outra face dos metadados: informações para a gestão da preservação digital. Encontros Bibli: Revista Eletrônica de Biblioteconomia e Ciência da Informação, v. 15, n. 30, p. 1-31, 2010. Disponível em: https://doi.org/10.5007/1518-2924.2010v15n30p1. Acesso em: 25 jul. 2021.

ZUBIAUR CARREÑO, F. Curso de Museologia. Espanha: Ediciones Trea, 2004.

\section{RE-DESIGN OF THE ATOM FOR THE DIGITAL}




\title{
CURATION IN DIGITAL ENVIRONMENTS AND MUSEOLOGICAL COMUNICATION
}

\begin{abstract}
Objective: This research aims to study the possibility of using AtoM for a description and representation of museum objects, specifically in historical museums. Methodology: The research has a participatory theoretical and exploratory characteristic with the conduction of a theoretical research on Digital Curation and museological description in the dialogic space of Information Science, and with a comparison of the descriptive forms of the AtoM with the descriptive model of the CIDOC Information Guidelines for Museums from 1995. Results: As a result, the AtoM represented the historical collection in a satisfactory manner and presented many functionalities, which allows adapting it to certain emerging problems. Conclusions: The research, whose results are now shown, revealed the answer to the presented question, and verified that the need for more indepth research into museological norms as they can contribute to a possible customization of the AtoM, capable of meeting the more complex needs of museum institutions and they favor democratization and access to cultural heritage, both in inperson and digital environments, for present and future generations.
\end{abstract}

Descriptors: Digital Curation. Information Design. Museum Collections. AtoM.

\section{REDISEÑO DEL ATOM PARA LA CURACIÓN DIGITAL EN AMBIENTES Y COMUNICACIÓN MUSEOLÓGICA}

\begin{abstract}
RESUMEN
Objetivo: Esta investigación tiene como objetivo estudiar la posibilidad de utilizar AtoM para una descripción y representación de objetos de museo, específicamente en museos históricos. Metodología: La investigación tiene un carácter teórico-exploratorio participativo con la realización de una investigación teórica sobre Curación Digital y descripción museológica en el espacio dialógico de las Ciencias de la Información, y con una comparación de las formas descriptivas de la AtoM con el modelo descriptivo de los Lineamientos de Información del CIDOC para museos desde 1995. Resultados: Como resultado, la AtoM representó la colección histórica de manera satisfactoria y presentó muchas funcionalidades, lo que permite adaptarla a ciertos problemas emergentes. Conclusiones: La investigación, cuyos resultados ahora se muestran, reveló la respuesta a la pregunta presentada, y verificó la necesidad de una investigación más profunda de las normas museológicas, ya que pueden contribuir a una posible personalización de la AtoM, capaz de satisfacer las necesidades más complejas de las instituciones museísticas y favorecen la democratización y el acceso al patrimonio cultural, tanto en entornos presenciales como digitales, para las generaciones presentes y futuras.
\end{abstract}

Descriptores: Curaduría Digital. Diseño de Información. Colecciones de Museos. AtoM.

Recebido em: 26.07.2021

Aceito em: 09.12.2021 